\title{
Digitally-Controlled Bondwire Inductor with High Quality Factor and Wide Tuning Range
}

\author{
Yonggoo Lee $\cdot$ Bomson Lee
}

\begin{abstract}
A tunable bondwire inductor (TBI) with high-quality factor and wide tuning range is presented. The proposed TBI is fabricated on a single chip by combining a single-pole four-throw (SP4T) switch integrated circuit (IC) and four bondwire inductors on a package substrate. The SP4T switch IC is fabricated using $180 \mathrm{~nm}$ silicon-on-insulator (SOI) complementary metal-oxide-semiconductor (CMOS) technology. The fabricated TBI chip exhibits a 521\% tuning range of inductance from 1.77 to $11 \mathrm{nH}$ at $0.1 \mathrm{GHz}$ and a relatively highquality factor. To the knowledge of the authors, the results of this work demonstrate the best combined performance of inductance tuning range and quality factor.
\end{abstract}

Key Words: Bondwire, Digitally-Controlled, High Quality Factor, Tunable Inductor, Wide Tuning Range.

\section{INTRODUCTION}

With increasing demands for high data rate services and the miniaturization of portable radio devices, the challenge of supporting multiple air interface technologies that enable compact multi-mode multi-band devices has become critical $[1,2]$. Currently, the market for electrically controllable matching circuits, tunable voltage-controlled oscillators (VCOs), tunable filters, and multi-band power amplifier modules (PAM) is growing rapidly [3-5]. Digitally tunable capacitors using complementary metal-oxide-semiconductors (CMOS) or microelectromechanical system (MEMS) switches have been widely used to meet these technical trends [6-8].

A digitally tunable inductor can be realized by physically changing the metal line length of an inductor with switches. Losses of the switches and metal lines have always been limiting factors in commercializing high-quality (Q) tunable inductors.
MEMS-applied tunable inductors have been studied due to their low losses $[9,10]$. However, they suffer from several drawbacks, such as complexity, difficulty in monolithic integration with other ICs, and reliability problems [11, 12]. Analog control with MEMS actuators and digital control with MOS switches have been employed to realize the tunable inductors [13-15], but these inductors have drawbacks in Q-factor, tuning range, and action voltage.

We propose a high-Q and wide tunable bondwire inductor (TBI) digitally controlled by RF CMOS switches. The bondwire inductors are adopted because their self-resistance and standard manufacturing process cost are much lower than those of spiral inductors $[16,17]$. The RF switches are designed using $180 \mathrm{~nm}$ silicon-on-insulator (SOI) CMOS technology to minimize their turn-on resistance. The performance of the proposed TBI is compared with other research results.

Manuscript received March 24, 2020 ; Revised May 13, 2020 ; Accepted June 24, 2020. (ID No. 20200324-040J)

Department of Electronic Engineering, Kyung Hee University, Yongin, Korea.

"Corresponding Author: Bomson Lee (e-mail: bomson@khu.ac.kr)

This is an Open-Access article distributed under the terms of the Creative Commons Attribution Non-Commercial License (http://creativecommons.org/licenses/by-nc/4.0) which permits unrestricted non-commercial use, distribution, and reproduction in any medium, provided the original work is properly cited.

(c) Copyright The Korean Institute of Electromagnetic Engineering and Science. All Rights Reserved. 


\section{DESIGN OF THE TUNABLE BONDWIRE INDUCTOR}

The basic schematic of the proposed TBI and the related equivalent circuits are shown in Fig. 1 . The RF switches $\left(S_{1}, S_{2}\right.$, $\left.\cdots, S_{N}\right)$ and inductors $\left(L_{1}, L_{2}, \cdots, L_{N}\right)$ are connected in series, which are connected in parallel between nodes $L_{\text {in }}$ and $L_{\text {out }} L_{p k g 1}$ and $L_{p k g}$ are the inductance of the bondwire used to package the switch integrated circuit (IC), $M_{i j}$ is the mutual inductance between $i$ th and $j$ th inductors, and $R_{o n}$ is the resistance for the switch "on" state $[18,19]$. The CMOS switch is made of 12 field-effect transistors (FETs) stacked for a high-power handling capability of up to $35 \mathrm{dBm}$. It is designed to have low $R_{o n}$ with an enlarged gate width for a high $\mathrm{Q}$ characteristic. The bondwire inductor is based on the single $\pi$-model [20]. When the number of inductors connected in parallel increases, the total inductance decreases, and the role of the low-loss $L_{p k g 1}$ becomes more important. The overall $\mathrm{Q}$ characteristic of the proposed TBI significantly depends on the resistance of the bondwire $\left(L_{p k g 1}\right.$ in Fig. 1$)$ used to package the switch IC. To reduce-

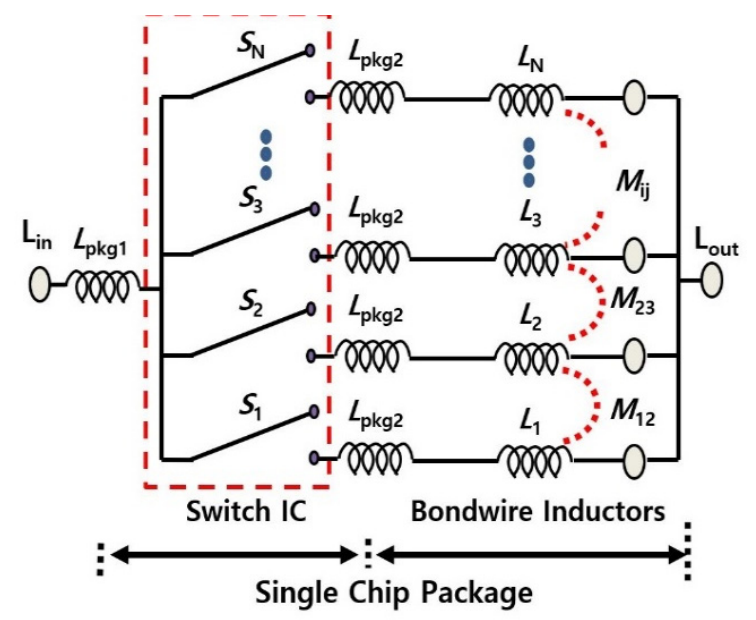

(a)

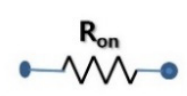

Switch Equivalent Circuit at ON state

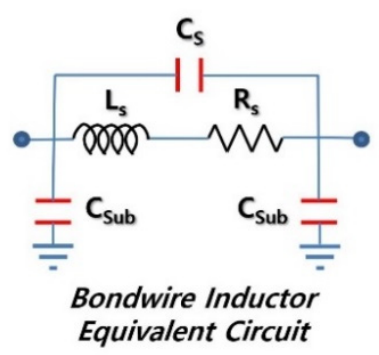

(b)

Fig. 1. (a) Basic schematic of the tunable inductor and (b) the related equivalent circuits. the resistance, double bonding wire is used. This has been found to significantly enhance the overall Q. Spiral inductors on CMOS substrates usually have low Q-factors because of their high conductor loss, caused by thin metal lines and high dielectric loss. In order to solve these electrical problems, the proposed TBI is designed on a package substrate. The schematic diagram of this proposed TBI is shown in Fig. 2. The positions of the four bondwire inductors achieve a high $\mathrm{Q}$ factor by optimizing the configuration of the TBI using an electromagnetic (EM) field simulator that takes into account mutual inductance.

For the wide tuning range and monotonous increase of inductance, the final inductance values for the single-pole fourthrow (SP4T) switch IC and four bondwire inductors are $L_{p k g 1}$ $=0.5 \mathrm{nH}, L_{1}=4.7 \mathrm{nH}, L_{2}=6 \mathrm{nH}, L_{3}=10.5 \mathrm{nH}$, and $L_{4}=3.2$ $\mathrm{nH}$. These inductance values have been finalized with EMsimulated optimization using a High-Frequency Structure Simulator (HFSS; Ansys Inc., Canonsburg, PA, USA) and starting from a theoretical calculation. The bondwire inductors are implemented on a chip-on-board (COB) substrate with low-loss dielectric material and a thick top metal layer. As such, the loss for the TBI becomes smaller than that for the wafer-level bondwire inductor. Bondwire inductors with low inductance are more sensitive to the internal resistance of the RF switch than those with high inductance. Thus, the switch $S_{4}$ for the inductor $L_{4}$ is designed to have the lowest internal $R_{o n}$ among the four used switches. The SP4T switch IC is controlled through a 3wire (clock, data, and enable) serial peripheral interface (SPI) and is usually powered using $V_{d d}$ (Fig. 2) of about $3.3 \mathrm{~V}$.

\section{FABRICATION AND MEASUREMENT RESULTS}

A prototype TBI was fabricated using a $\mathrm{COB}$ assembly process to verify the feasibility of the proposed configuration. Photographs of the prototype are shown in Fig. 3. The size of the module consisting of four bondwire inductor arrays and an SP4T RF switch was $2.0 \times 2.4 \times 0.8 \mathrm{~mm}^{3}$. The size of the

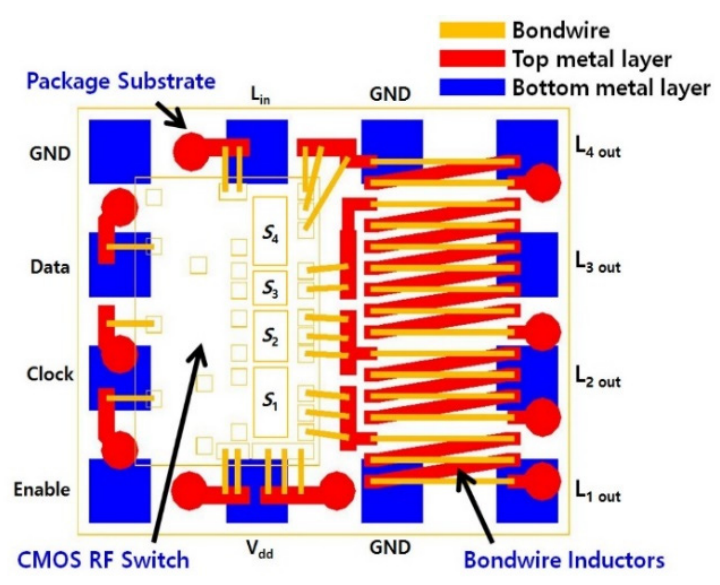

Fig. 2. Diagram of the proposed TBI structure. 


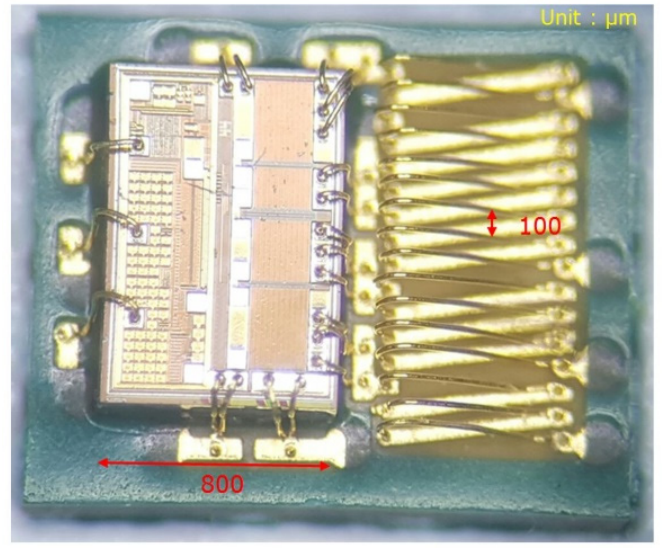

(a)

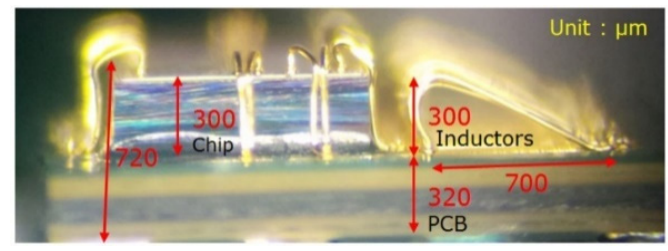

(b)

Fig. 3. Microphotograph of the TBI module: (a) top view and (b) side view.

fabricated SP4T switch with the SPI communication block was $1.3 \times 0.8 \times 0.3 \mathrm{~mm}^{3}$. It used thin-film SOI $180 \mathrm{~nm}$ CMOS RF switch technology. During fabrication of the TBI, the switch chip was die-bonded on a package substrate (Fig. 2), and the wire bonding for the bondwire inductor and chip packaging was performed using $1 \mathrm{mil}(25.4 \mu \mathrm{m})$ diameter gold wire. The separation between the bondwires is $100 \mu \mathrm{m}$. The height of the bondwires is $300 \mu \mathrm{m}$, and the total length of a single bondwire is $1.06 \mathrm{~mm}$. The fabricated chip was measured using a Keysight E5071C network analyzer (Keysight Technologies Inc., Santa Rosa, CA, USA) with a short-open-load-through (SOLT) calibration and de-embedding.

Table 1 lists the performance of the TBI depending on states of 4-bit switch combinations. The fabricated TBI chip exhibits a variable inductance from 1.77 to $11 \mathrm{nH}$ at $0.1 \mathrm{GHz}$. The maximum Q of 29.5 occurs at $2.1 \mathrm{GHz}$ in state 15, where the self-resonant frequency (SRF) is $4.42 \mathrm{GHz}$.

The measured inductances and Q-factors are shown in Fig. 4 as a function of frequency from 0 to $3.5 \mathrm{GHz}$. The measured inductance of the TBI shows a monotonically increasing characteristic. In Fig. 4(b), the states with two or more bondwire inductors are shown to have higher $\mathrm{Q}$ characteristics than those with one bondwire inductor. These high $\mathrm{Q}$ characteristics are obtained by minimizing the turn-on resistance of the RF switch with an enlarged gate width, minimizing the self-resistance of package bondwire with a double bondwire connection, and optimizing the configuration of the TBI using the 3D EM simulation tool.

The measured inductances and Q-factors for all states at 1.5 $\mathrm{GHz}$ and $2 \mathrm{GHz}$ are shown in Fig. 5. A higher Qoccurs with more parallel-connected inductors, as in states 11 and 15 . When the number of parallel inductors increases, the TBI has an additional magnetic flux due to the mutual coupling. The parallel inductance by the bondwire inductors becomes small so that the effect of the inductance of $L_{p k g 1}$ used as a package is relatively high. Therefore, a higher $\mathrm{Q}$ is achieved with more parallelconnected TBIs.

In Table 2, the performance of the proposed TBIs are com-

Table 1. Performance depending on switch states

\begin{tabular}{|c|c|c|c|c|c|}
\hline Switch state & Combination of inductors & $\begin{array}{c}\mathrm{L}(\mathrm{nH}) \\
@ 0.1 \mathrm{GHz}\end{array}$ & $\begin{array}{c}\text { Peak Q } \\
\left(Q_{\text {peak }}\right)\end{array}$ & $\begin{array}{l}\text { Freq. } \\
@ \mathrm{Q}_{\text {peak }}\end{array}$ & $\begin{array}{c}\mathrm{SRF} \\
(\mathrm{GHz}) \\
\end{array}$ \\
\hline 1 & $L_{1}$ & 5.20 & 10.8 & 1.30 & 2.47 \\
\hline 2 & $L_{2}$ & 6.50 & 8.6 & 1.07 & 2.24 \\
\hline 3 & $L_{1} / / L_{2}$ & 3.14 & 17.1 & 1.24 & 3.41 \\
\hline 4 & $L_{3}$ & 11.00 & 6.2 & 0.72 & 1.74 \\
\hline 5 & $L_{1} / / L_{3}$ & 3.75 & 13.3 & 1.30 & 2.94 \\
\hline 6 & $L_{2} / / L_{3}$ & 4.32 & 11.0 & 1.23 & 2.54 \\
\hline 7 & $L_{1} / / L_{2} / / L_{3}$ & 2.61 & 14.4 & 1.44 & 3.07 \\
\hline 8 & $L_{4}$ & 3.70 & 15.3 & 1.24 & 2.95 \\
\hline 9 & $L_{1} / / L_{4}$ & 2.40 & 21.3 & 1.85 & 4.42 \\
\hline 10 & $L_{2} / / L_{4}$ & 2.59 & 19.1 & 1.72 & 2.94 \\
\hline 11 & $L_{1} / / L_{2} / / L_{4}$ & 1.95 & 28.0 & 2.01 & 4.40 \\
\hline 12 & $L_{3} / / L_{4}$ & 2.95 & 12.4 & 1.44 & 2.85 \\
\hline 13 & $L_{1} / / L_{3} / / L_{4}$ & 2.11 & 25.7 & 1.85 & 4.43 \\
\hline 14 & $L_{2} / / L_{3} / / L_{4}$ & 2.24 & 23.1 & 1.90 & 3.41 \\
\hline 15 & $L_{1} / / L_{2} / / L_{3} / / L_{4}$ & 1.77 & 29.5 & 2.10 & 4.42 \\
\hline
\end{tabular}




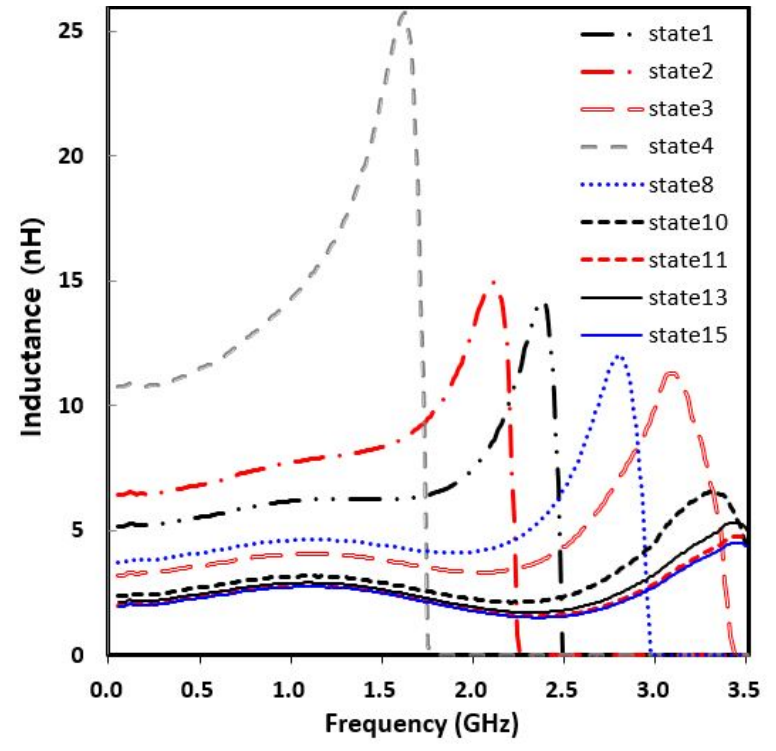

(a)

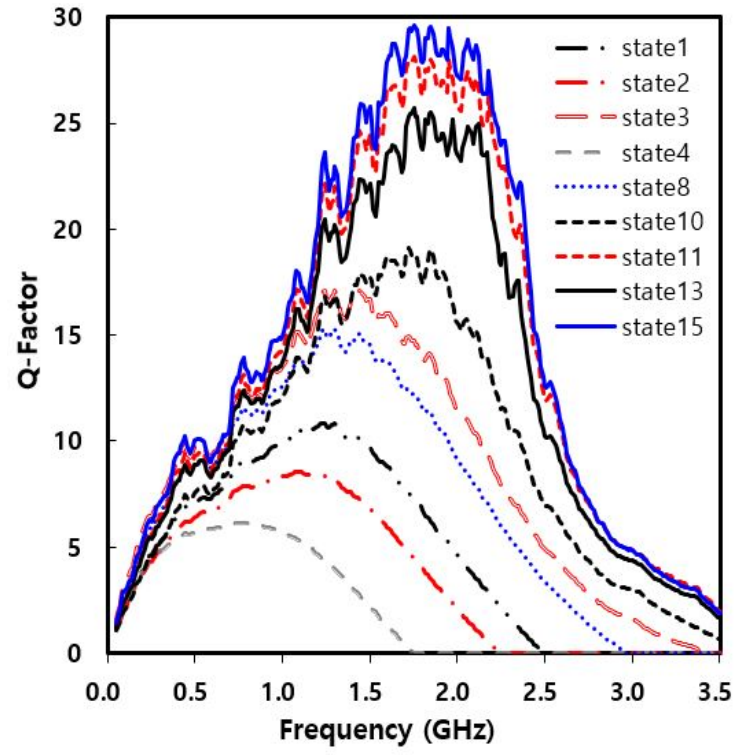

(b)

Fig. 4. Measured inductances (a) and Q-factors (b) for different switching states.

Table 2. Comparison of tunable inductors

\begin{tabular}{|c|c|c|c|c|c|c|}
\hline \multirow{2}{*}{ Ref., year } & \multicolumn{2}{|c|}{ Control } & \multirow{2}{*}{$\begin{array}{l}\text { Size } \\
\left(\mathrm{mm}^{2}\right)\end{array}$} & \multirow{2}{*}{$\begin{array}{c}\text { Primary } \\
\text { inductance } \\
(\mathrm{nH})\end{array}$} & \multirow{2}{*}{$\begin{array}{c}\text { Tuning } \\
\text { range } \\
(\%)\end{array}$} & \multirow{2}{*}{$\begin{array}{l}\text { Q-factor } \\
\text { / freq. } \\
(\mathrm{GHz})\end{array}$} \\
\hline & Type & Method & & & & \\
\hline [13], 2003 & Digital CMOS & $1.6 \mathrm{~V}$ & $0.2 \times 0.22$ & 8 & $<200$ & $7 / 2$ \\
\hline$[14], 2005$ & Analog MEMS & $7 \mathrm{~V}$ & $2.2 \times 4$ & 8.5 & $<30$ & $35 / 2$ \\
\hline [21], 2008 & Digital MEMS & $40 \mathrm{~V}$ & - & 1.1 & 47 & $45 / 6$ \\
\hline [20], 2009 & Analog MEMS & 0-11 mW & $0.25 \times 0.25$ & 0.72 & $<100$ & $26 / 15$ \\
\hline [23], 2009 & Digital MEMS & $60 \mathrm{~V}$ & $0.4 \times 0.69$ & 0.75 & $<80$ & $8.5 / 4$ \\
\hline [15], 2010 & Analog MEMS & $9 \mathrm{~V}$ & - & 0.36 & $<78$ & $17.6 / 3.9$ \\
\hline$[22], 2012$ & Analog MEMS & $20 \mathrm{~V}$ & $1.6 \times 1.6$ & 3 & $<233$ & $12.9 / 5.3$ \\
\hline [24], 2012 & Analog MEMS & $\sim 1.2 \mathrm{~A}$ & $8 \times 8$ & 186 & $<16$ & $23 / 0.06$ \\
\hline [25], 2013 & Analog MEMS & Liquid injected & - & 1.3 & $<60$ & $18 / 12$ \\
\hline [26], 2013 & Analog MEMS & RF $0.7 \mathrm{~W}$ & $7 \times 7$ & 37.5 & $<12$ & $17 / 1.2$ \\
\hline [27], 2018 & Digital Memristor & -0.4 to $3 \mathrm{~V}$ & - & 4.6 & $<296$ & $18 / 5$ \\
\hline Proposed & Digital CMOS & $3.3 \mathrm{~V}$ & $2 \times 2.4$ & 1.77 & $<521$ & $29.5 / 2$ \\
\hline
\end{tabular}

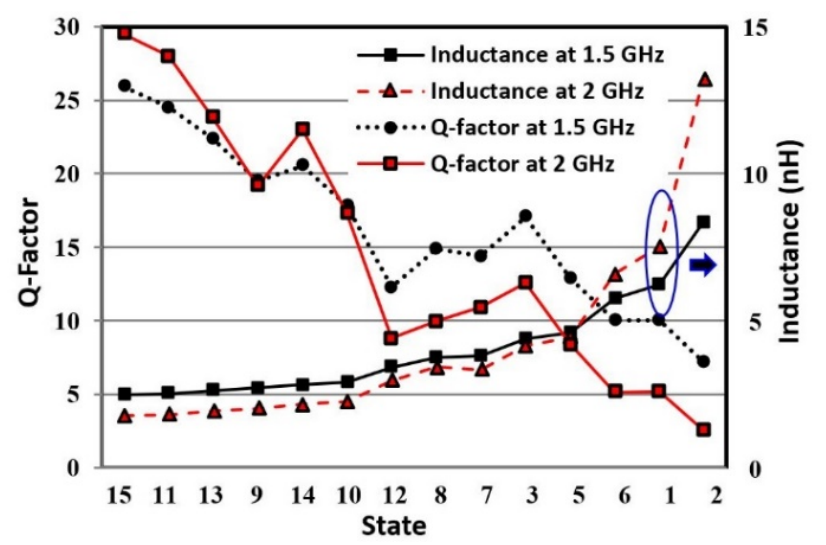

Fig. 5. Measured inductances and $\mathrm{Q}$ factors for all states at 1.5 $\mathrm{GHz}$ and $2 \mathrm{GHz}$. pared with others $[13-15,20-27]$ in terms of primary inductance, size, tuning range, Q-factor, and action voltage. Due to the narrow tuning range characteristics below 233 and the need for voltage above $7 \mathrm{~V}$ or special operating signals, the tunable inductors [14, 15, 20-26] using MEMS actuators have limitations for general product applications. In Park et al. [13], a multi-layer stacked inductor switched by MOSFETs is reported. The main drawback of this device is its low $Q_{2}$ caused by parasitic losses of the transistor. In Wainstein and Kvatinsky [27], two topologies, a memristive-via switched tunable inductor and a multi-layer stacked inductor tuned by RF memristive switches, are proposed and simulated using Advanced Design System (ADS). By improving the parasitic losses of the switch, Wain- 
stein and Kvatinsky [27] obtain a higher Q than Park et al. [13]. TBI has the advantages of complete SPI control, wide tuning range by 4-bit control, and high Q using bonding wire inductors. Overall, the proposed TBI is superior to others.

\section{CONCLUSION}

The proposed tunable bondwire inductor has been shown to exhibit a wide (521\%) tuning range, from 1.77 to $11 \mathrm{nH}$ at 0.1 GHz. It has also shown high Q-factors, with a maximum of 29.5 when four inductors are all connected in parallel. These competitive results have been obtained using thin-film SOI 180 $\mathrm{nm}$ CMOS RF switch technology and wire bond technology.

The proposed tunable inductor is a promising key component for such uses as electrically controllable RF circuits, filters with wide tuning range, and matching circuits for various applications.

This research was supported by the Ministry of Science and ICT, Korea, under the Information Technology Research Center support program (No. IITP-2020-2016-0-00291) supervised by the Institute for Information \& Communications Technology Planning \& Evaluation (IITP).

\section{REFERENCES}

[1] N. Cheng and J. P. Young, "Challenges and requirements of multimode multiband power amplifiers for mobile applications," in Proceedings of 2011 IEEE Compound Semiconductor Integrated Circuit Symposium (CSICS), Waikoloa, HI, 2011, pp. 1-4.

[2] N. A. Kamsani, V. Thangasamy, M. F. Bukhori, and S. Shafie, "A multiband 130nm CMOS second order band pass filter for LTE bands," in Proceedings of 2015 IEEE International Circuits and Systems Symposium (ICSyS), Langkawi, Malaysia, 2015, pp. 100-105.

[3] P. Starke, D. Fritsche, C. Carta, and F. Ellinger, "A passive tunable matching filter for multiband RF applications demonstrated at 7 to $14 \mathrm{GHz}$," IEEE Microwave and Wireless Components Letters, vol. 27, no. 8, pp. 703-705, 2017.

[4] E. Arabi, X. Jiao, K. Morris, and M. Beach, "Analysis of the coverage of tunable matching networks with three tunable elements," in Proceedings of 2017 IEEE MTT-S International Microwave Symposium (IMS), Honololu, HI, 2017, pp. 904-906.

[5] S. Yokano, T. Chiba, S. Nagai, K. Hirabayashi, and N. Adachi, "A wide range tunable bandpass filter using imaginary resonance phenomena," in Proceedings of 2018 AsiaPacific Microwave Conference (APMC), Kyoto, Japan, 2018, pp. 606-608.

[6] D. H. Baek, Y. Eun, D. S. Kwon, M. O. Kim, T. Chung, and J. Kim, "Widely tunable variable capacitor with switching and latching mechanisms," IEEE Electron Device Letters, vol. 36, no. 2, pp. 186-188, 2015.

[7] T. W. Lin, K. K. W. Low, R. Gaddi, and G. M. Rebeiz, "High-linearity 5.3-7.0 GHz 3-pole tunable bandpass filter using commercial RF MEMS capacitors," in Proceedings of 2018 48th European Microwave Conference (EuMC), Madrid, Spain, 2018, pp. 555-558.

[8] Y. K. Jung and B. Lee, "Design of tunable optimal load circuit for maximum wireless power transfer efficiency," Microwave and Optical Technology Letters, vol. 56, no. 11, pp. 2619-2622, 2014.

[9] M. M. Teymoori and J. M. Ahangarkolaei, "MEMS tunable inductors: a survey," Australian Journal of Basic and Applied Sciences, vol. 5, no. 12, pp. 1868-1878, 2011.

[10] N. Habbachi, H. Boussetta, M. A. Kallala, P. Pons, A. Boukabache, and K. Besbes, "Leakage current effect on fixed and tunable solenoid RF MEMS inductors," in Proceedings of 2017 International Conference on Engineering \& MIS (ICEMIS), Monastir, Tunisia, 2017, pp. 1-6.

[11] V. Turgul, T. Nesimoglu, and B. S. Yarman, "A study on $\mathrm{RF} /$ microwave tunable inductor topologies," in Proceedings of 2013 13th Mediterranean Microwave Symposium (MMS), Saida, Lebanon, 2013, pp. 1-4.

[12] R. R. Manikandan and V. N. R. Vanukuru, "A high performance switchable multiband inductor structure for LCVCOs," in Proceedings of 2017 30th International Conference on VLSI Design and 2017 16th International Conference on Embedded Systems (VLSID), Hyderabad, India, 2017, pp. 253-258.

[13] P. Park, C. S. Kim, M. Y. Park, S. D. Kim, and H. K. Yu, "Variable inductance multilayer inductor with MOSFET switch control," IEEE Electron Device Letters, vol. 25, no. 3, pp. 144-146, 2004.

[14] N. Sarkar, D. Yan, E. Horne, H. Lu, M. Ellis, J. B. Lee, R. Mansour, A. Nallani, and G. Skidmore, "Microassembled tunable MEMS inductor," in Proceedings of 18th IEEE International Conference on Micro Electro Mechanical Systems (MEMS), Miami Beach, FL, 2005, pp. 183-186.

[15] D. M. Fang, X. H. Li, Q. Yuan, and H. X. Zhang, "Design, simulation, and characterization of variable inductor with electrostatic actuation fabricated by using surface micromachining technology," IEEE Transactions on Electron Devices, vol. 57, no. 10, pp. 2751-2755, 2010.

[16] Y. G. Lee, S. K. Yun, and H. Y. Lee, "Novel high-Q bondwire inductor for MMIC," in Proceedings of International Electron Devices Meeting 1998 Technical Digest (Cat. No. 98CH36217), San Francisco, CA, 1998, pp. 548- 
551.

[17] K. C. Lin, H. K. Chiou, P. C. Wu, W. H. Chen, C. L. Ko, and Y. Z. Juang, "2.4-GHz complementary metal oxide semiconductor power amplifier using high-quality factor wafer-level bondwire spiral inductor," IEEE Transactions on Components, Packaging and Manufacturing Technology, vol. 3, no. 8, pp. 1286-1292, 2013.

[18] Z. Cheng, G. Yan, W. Ni, D. Zhu, H. Ni, J. Li, S. Chen, and G. Liu, "15158A SP6T RF switch based on IBM SOI CMOS technology," Journal of Semiconductors, vol. 37, no. 5, article no. 055007, 2016.

[19] A. S. Cardoso, P. S. Chakraborty, A. P. Omprakash, N. Karaulac, P. Saha, and J. D. Cressler, "On the cryogenic performance of ultra-low-loss, wideband SPDT RF switches designed in a $180 \mathrm{~nm}$ SOI-CMOS technology," in Proceedings of 2014 SOI-3D-Subthreshold Microelectronics Technology Unified Conference (S3S), Millbrae, CA, 2014.

[20] J. I. Kim and D. Peroulis, "Tunable MEMS spiral inductors with optimized RF performance and integrated largedisplacement electrothermal actuators," IEEE Transactions on Microwave Theory and Tecbniques, vol. 57, no. 9, pp. 2276-2283, 2009.

[21] M. Rais-Zadeh, P. A. Kohl, and F. Ayazi, "MEMS switched tunable inductors," Journal of Microelectromechanical Systems, vol. 17, no. 1, pp. 78-84, 2008.

[22] S. S. Bedair, J. S. Pulskamp, C. D. Meyer, M. Mirabelli, R.

Yonggoo Lee

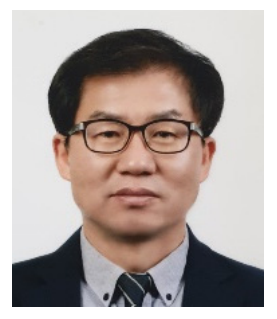

received a B.S. degree in Electronics Engineering from Ajou University, Suwon, Korea, in 1994. From 1994 to 1996, he was with Hyundai Mobis Technical Center, Yongin, Korea. He received an M.S. degree in Electronics Engineering from Ajou University, Suwon, Korea, in 1998. From 1998 to 2001, he was with CS Corporation, Seongnam, Korea. From 2001 to 2014, he was with GigaLane Company, Gyeonggi-do, Korea, as its Chief Technology Officer. He is currently pursuing a Ph.D. degree in Electronics Engineering from Kyung Hee University, Yongin, Korea. He founded WithWave Company, Suwon, Korea, in 2014, and manages it as Chief Executive Officer. His current research interests include RF tunable devices, microwave communication system, RF MEMS devices, millimeter-wave interconnections, and electromagnetic measurement standards.
G. Polcawich, and B. Morgan, "High-performance micromachined inductors tunable by lead zirconate titanate actuators," IEEE Electron Device Letters, vol. 33, no. 10, pp. 1483-1485, 2012.

[23] D. H. Choi, H. S. Lee, and J. B. Yoon, "Linearly variable inductor with RF MEMS switches to enlarge a continuous tuning range," in Proceedings of 2009 International SolidState Sensors, Actuators and Microsystems Conference (TRANSDUCERS), Denver, CO, 2009, pp. 573-576.

[24] B. Assadsangabi, M. M. Ali, and K. Takahata, "Ferrofluid-based variable inductor," in Proceedings of 2012 IEEE 25th International Conference on Micro Electro Mechanical Systems (MEMS), Paris, France, 2012, pp. 1121-1124.

[25] F. Banitorfian, F. Eshghabadi, A. Abd Manaf, P. Pons, N. M. Noh, M. T. Mustaffa, and O. Sidek, "A novel tunable water-based RF MEMS solenoid inductor," in Proceedings of 2013 IEEE Regional Symposium on Micro and Nanoelectronics (RSM), Langkawi, Malaysia, 2013, pp. 58-61.

[26] M. S. M. Ali, B. Bycraft, A. Bsoul, and K. Takahata, "Radio-controlled microactuator based on shape-memoryalloy spiral-coil inductor," Journal of Microelectromechanical Systems, vol. 22, no. 2, pp. 331-338, 2012.

[27] N. Wainstein and S. Kvatinsky, "TIME: tunable inductors using memristors," IEEE Transactions on Circuits and Systems I: Regular Papers, vol. 65, no. 5, pp. 1505-1515, 2018.

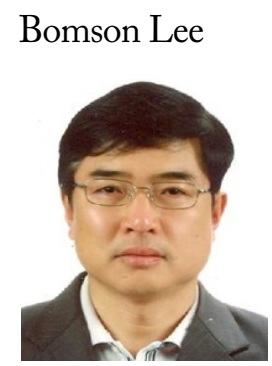

received a B.S. degree in Electrical Engineering from Seoul National University, Seoul, Korea, in 1982. From 1982 to 1988, he was with the Hyundai Engineering Company Ltd., Seoul, Korea. He received M.S. and Ph.D. degrees in Electrical Engineering from the University of Nebraska, Lincoln, NE, USA, in 1991 and 1995, respectively. In 1995, he joined the faculty at Kyung Hee University, where he is currently a professor in the Department of Electronics and Radio Engineering. From 2007 to 2008, he was the chair of the technical group for microwave and radio wave propagation in the Korea Institute of Electromagnetic Engineering \& Science (KIEES). In 2010, he was an Editor-in-Chief of the Journal of the Korean Institute of Electromagnetic Engineering and Science. In 2018, he served as the president of KIEES. His research interests include microwave antennas, RFID tags, microwave passive devices, wireless power transfer, and metamaterials. 